\title{
HER2/Neu Protein Over-Expression in Patients with Gastric and Gastro- Esophageal Junction Carcinoma Seen at Kenyatta National Hospital, Kenya
}

\author{
Ali Hussein A $^{1}$, Rogena Emily ${ }^{*}$, Omulo TM ${ }^{1}$ and Ndaguatha PLW ${ }^{1}$ \\ ${ }^{1}$ Department of Surgery, School of Medicine, College of Health Sciences, University of Nairobi, Kenya \\ ${ }^{2}$ Department of Human Pathology, School of Medicine, College of Health Sciences, University of Nairobi, Kenya
}

*Corresponding author: Dr. Rogena Emily, Senior lecturer, Department of Human Pathology, School of Medicine, College of Health Sciences, University of Nairobi, Hospital Road, PO BOX 55050, Nairobi, Kenya 00200, Kenya, Tel: +254 721674 647; E-mail: rogena_emily@uonbi.ac.ke

Received date: Jun 28, 2014, Accepted date: Aug 28, 2014, Published date: Sep 06, 2014

Copyright: ( 2014 Hussein AA, et al. This is an open-access article distributed under the terms of the Creative Commons Attribution License, which permits unrestricted use, distribution, and reproduction in any medium, provided the original author and source are credited.

\begin{abstract}
Background: Gastric cancer in Kenya is ranked third in both males and females. Most patients present clinically with advanced unsusceptible disease have poor prognosis despite administration of standard chemotherapy. Human epidermal growth factor receptor-2 (HER-2) over expression in gastric cancer is related to poor outcome. Advances in molecular therapy, have identified HER-2 to be an important component in the treatment of advanced gastric cancer. The prevalence of HER-2 in Kenya is unknown.
\end{abstract}

Objective: To determine the prevalence of HER-2 overexpression in patients with gastric and gastrooesophageal junction carcinoma at Kenyatta National Hospital.

Methodology: Descriptive Cross sectional study on patients with histological diagnosis from endoscopic/ resection specimens of gastric or GEJ cancer at $\mathrm{KNH}$. A sample of 66 patients was selected by progressive sampling. Approval was obtained from the $\mathrm{KNH} / \mathrm{UON}$ ethics and research committee. Data was collected using a pretested questionnaire. All tissue blocks were tested for HER-2 receptor protein using IHC. Data entry and analysis was done via SPSS version 21.0.

Results: Study sample of 66 patients were included in the study with a mean age of 60.7 years and males consisting of $66.7 \%$. 42 specimens were obtained from OGD and 24 from surgically resected specimens. Approximately $91 \%$ of the tumours were located in the gastric region. Gastric adenocarcinoma accounted for $89.4 \%$ $(\mathrm{N}=59)$ mainly intestinal $(78.8 \%, \mathrm{~N}=52)$ and diffuse $(9.1 \%, \mathrm{~N}=6)$ while $1.5 \%(\mathrm{~N}=1)$ was adeno-squamous. HER-2 over-expression was diagnosed in $42.4 \%(\mathrm{~N}=28)$ of patients. HER-2 over-expression was not significantly associated with age $(P=0.844)$ and gender $(P=0.682)$. The anatomical site was not significantly associated with HER-2 over-expression ( $P=1$ ). HER-2 over-expression was found mostly in adenocarcinoma (96.4\%) compared to $3.6 \%$ in adeno-squamous, with intestinal type showing highest rate of over-expression (87.5\%) compared to diffuse $(12.5 \%)$.

Conclusion: HER-2 over-expression was found to be higher in our study $(42.4 \%)$ compared to most of the studies. HER-2 over-expression is observed predominantly in intestinal type of gastric and GEJ adenocarcinomas.

Keywords: Gastric cancer; HER-2; Anti-cancer therapy; Molecular targeted therapy

\section{Background and Literature Review}

Gastric cancer is the second leading cause of cancer death worldwide [1]. The highest incidence is found in Eastern Europe, Eastern Asia and South Africa, the lowest in North America [2].

The major risk factors for gastric cancer are male sex, Helicobacter pylori infection, smoking, high levels of dietary salt and nitrates, medical conditions such as atrophic gastritis and pernicious anemia, positive family history of gastric cancer and previous gastrectomy3. Obesity has been associated with gastric cardiac and junctional tumours, most likely through increased gastro-oesophageal reflux and subsequent Barrett's metaplasia [3]. Tumours of the gastro oesophageal junction are classified as gastric cancer. Adenocarcinoma of the stomach accounts for $10 \%$ of all cancer worldwide [4].
Gastric cancer is more common in males than in females with a distribution rate of approximately 2:1 respectively.

Incidence data from Africa are weak, reliable estimation of cancer incidences is difficult to obtain and few established cancer registers are available.

According to the Nairobi cancer registry, gastric cancer is ranked third in both males and females after cancer of the prostate and oesophagus in males and cancer of the breast and cervix in females. In males, gastric cancer accounts for $7.3 \%$ of all male cancers and $9.5 \%$ in females5. Clinically, most patients present with advanced gastric cancer and prognosis remains poor. The overall 5 year survival rate is about $27 \%$, with stage 1 being $90 \%$ but hardly discovered clinically. Stage $2-3$ disease is $20 \%-50 \%$ and $5 \%-10 \%$ for stage 4 [6].

In non-metastatic disease, surgery is the mainstay of treatment but recurrences are common despite curative resection hence adjuvant radio-chemotherapy is recommended [6]. 
Citation: Hussein AA, Emily R, Omulo TM, Ndaguatha PLW (2014) HER2/Neu Protein Over-Expression in Patients with Gastric and GastroEsophageal Junction Carcinoma Seen at Kenyatta National Hospital, Kenya. J Carcinog Mutagen 5: 186. doi: $10.4172 / 2157-2518.1000186$

Page 2 of 10

The discovery of new targeted therapies and chemotherapy agents, together with increasing knowledge of biological pathways underlying GC and the ability to predict which patients or tumours will respond to which treatment, has led to improved GC patient outcomes. Targeted therapies have emerged as a new hope in cancer management during recent years [6].

Molecular targeted therapy advances have identified HER2 as an important target for anti-cancer therapy in gastric cancer. HER-2 over expression in gastric cancer has been reported to range widely from $6 \%$ to $45 \% 7$. HER2 over-expression is a negative prognostic factor in Gastric and GEJ carcinoma, correlating with a poor survival [4].

In Kenya, prevalence of HER-2 over expression has not been established hence the therapeutic utility of targeted therapies still remains unclear. The study aims to determine the prevalence of HER2 over expression in patients with gastric and gastro-oesophageal junction cancer presenting at Kenyatta National Hospital.

Gastric cancer is the fourth most common malignancy and second leading cause of cancer deaths world-wide, hence a significant global health problem [1].

The world age standardized incidence rates (WASR) of gastric cancer of various African population is as follows:

\begin{tabular}{|l|l|l|l|}
\hline Location & Year & WASR Males & WASR Females \\
\hline Kenya, Meru [8]8 & $1991-1993$ & 14.3 & 7.1 \\
\hline Mali, Bamako [9] & $1988-1992$ & 19.6 & 11.1 \\
\hline Zimbabwe, Harare [10] & $1993-1995$ & 12.3 & 11 \\
\hline $\begin{array}{l}\text { Uganda, Kyadondo } \\
\text { [11] }\end{array}$ & $1991-1994$ & 4.7 & 3.2 \\
\hline Algeria, Setif [9] & $1990-1993$ & 14.4 & 3.5 \\
\hline
\end{tabular}

Table 1: World age standardized incidence rate of gastric cancer in Africans. Source: stomach cancer in Africa 4.18; 372/cancer incidence in five continents, 8; 94-95.

HER-2 (Human Epidermal Growth Factor Receptor-2) is a protein encoded by the ERBB2 gene in humans. ERBB2 gene is a protooncogene located at the long arm of human chromosome 17 (17q12). Amplification or over expression of this gene has been shown to play an important role in the pathogenesis and progression of certain aggressive types of cancers such as breast and gastric. HER-2 has become an important biomarker and target of therapy for these cancers.

This gene is translated into $185 \mathrm{kD}$ membrane growth factor receptor protein, which transmits signals regulating normal cell growth, development and survival. The binding of several high affinity ligands to HER receptor-family members leads to receptor dimerization and activation of intracellular signaling through receptor tyrosine kinases. The amplification of HER-2 gene which translates to over-expression of HER-2 receptor protein on the cell membrane increases the likelihood of receptor dimerization and activation of these signaling pathways [12]. HER-2 is associated with excessive dimerization that contributes to cell survival, cell proliferation and tumorigenesis [13].

\section{HER-2 and Gastric Cancer}

HER-2 protein over-expression in gastric cancer was first described in 1986 using immunohistochemistry (IHC) [14].

In gastric and gastro-oesophageal junction carcinoma, HER-2 appears to be an important prognostic factor which is related to poor prognosis. Different studies have found HER-2 over- expression in gastric and gastro-oesophageal adenocarcinoma to be associated with increasing depth of invasion, lymph node involvement, distant metastases and poor survival [15]. However, there is conflicting information in this respect and not all studies have shown a clear association between HER2 over-expression and poor prognosis. HER2 protein over-expression and gene amplification are much more heterogeneous in gastric cancer compared to breast cancer hence its implications for the clinical testing of biopsy specimens [16].

Wide range of variation in prevalence of HER-2 has been demonstrated in various population, different histologic types and location of the tumour. Bang et al. [17] found HER-2 positivity rate of $22.1 \%$ in the Republic of Korea. This was similar with Europe 23.6\% and Asia $23.5 \%[18,19]$. Even higher prevalence of $53 \%$ and $91 \%$ has been reported $[20,21]$.

Varying prevalence in tumour site was seen in several studies. In a US population study, HER-2 over-expression was found to be $12 \%$ in gastric cancer and $10 \%$ in gastro-oesophageal junction cancer [22].

In Finland gastric cancer prevalence was at $12 \%$ and GEJ was at $24 \%$ [23], similar trend was seen in Spain recording a prevalence of $9.5 \%$ in gastric and $25 \%$ in GEJ [24]. Lordwick et al. did a multinational study and reported a prevalence of $18 \%$ in gastric and $32 \%$ in GEJ [25].

Variation in prevalence according to histologic types was also reported in over 5 studies. The prevalence of HER2 has been shown to be higher in intestinal than diffuse type of gastric cancer as illustrated in the table below (Table 2)

\begin{tabular}{|l|l|l|l|l|}
\hline \multirow{2}{*}{ Author } & Population & \multicolumn{2}{|l|}{ Histologic types } & \\
\cline { 3 - 5 } & & $\begin{array}{l}\text { Intestinal } \\
(+\%)\end{array}$ & $\begin{array}{l}\text { Diffuse } \\
(+\%)\end{array}$ & $\begin{array}{l}\text { Mixed/unknown } \\
(+\%)\end{array}$ \\
\hline Tanner [23] & Finland & 21.5 & 2 & 5 \\
\hline Gravalos [24] & Spain & 16 & 7 & 14 \\
\hline Lordwick [25] & International & 34 & 6 & 20 \\
\hline Matsubara [26] & Japan & 32.5 & 6 & \\
\hline Park [27] & Korea & 8 & 1 & \\
\hline
\end{tabular}

Table 2: Variation in prevalence of HER2 according to histological types of gastric cancer. Source Connection: HER-2 testing in gastric and oesophageal adenocarcinoma, $2010[15,48]$.

\section{HER-2 Status Assessment}

Accurate determination of HER-2 status is critical to ascertain which patients might benefit from targeted therapies. HER-2 status is typically measured by immunohistochemistry (IHC) or Fluorescent In Situ Hybridization (FISH) [28,29]. IHC is frequently utilized for HER-2 assessment due to the wider availability in routine diagnostic testing and cost implications compared to FISH. Moreover, FISH 
Citation: Hussein AA, Emily R, Omulo TM, Ndaguatha PLW (2014) HER2/Neu Protein Over-Expression in Patients with Gastric and GastroEsophageal Junction Carcinoma Seen at Kenyatta National Hospital, Kenya. J Carcinog Mutagen 5: 186. doi: $10.4172 / 2157-2518.1000186$

Page 3 of 10

shows higher sample related failure and is very sensitive to fixatives and duration of fixation.

Additionally, FISH documentation is a challenge due to the diminishing fluorescents signals on the slides [30]. A validated scoring system has been developed for HER-2 assessment in gastric cancer [18] based on the study done by Hoffman et al [18]. Consensus was reached and the following was recommended for scoring HER-2 over expression in gastric cancer. Cells that stain with a score of 0 or +1 are considered negative meaning they don't have amplification of the HER-2 gene thus do not overexpress the HER2 receptor protein. A score of +3 is confirmed overexpression while +2 denotes an equivocal positive score.

\section{Study Justification}

Gastric cancer remains the fourth most commonly diagnosed cancer and the second leading cause of cancer-related deaths worldwide $[42,43]$. The annual mortality attributed to stomach cancer worldwide is 803000 deaths. In Kenya gastric cancer is the third most common cancer [5].

The overall survival rate of gastric cancer remained poor until the introduction of multidisciplinary approaches and identification of novel targeted agents, which has continued to improve survival outcome. Trastuzumab is a monoclonal antibody that interferes with HER-2 receptor function. It has been shown to improve the survival of patients with advanced gastric cancer and prolong their lives by 2.7 months when added to standard chemotherapy than those patients who received chemotherapy alone $[17,44]$.

Patients with HER-2 positivity by IHC have been shown by other studies to have a longer survival (16 months) with addition of trastuzumab compared to chemotherapy alone (11.8 months) [40].

HER-2 over expression in gastric cancer has been reported to range widely from $6 \%$ to $45 \%$. Due to this wide range of prevalence, our own local prevalence needs to be evaluated. There is paucity of data on the prevalence of HER2 over expression in gastric and gastro-oesophageal junction cancer in the African population.

\section{Objectives of the Study}

\section{Broad objectives}

To HER-2 over-expression among patients with gastric and gastrooesophageal junction carcinoma at Kenyatta National Hospital.

\section{Specific objectives}

1. To determine the demographic pattern of tumour HER-2 overexpression in patients with gastric and gastro-oesophageal junction carcinoma at Kenyatta National Hospital.

2. To determine the histological type and anatomical site of the tumour at which HER-2 over-expression is manifest.

3. To determine the percentage of gastric and gastro-oesophageal junction carcinoma that over-express HER-2.

\section{Materials and Methods}

\section{Study area}

The setting of the study was at Kenyatta National Hospital which is a teaching and main tertiary referral hospital in Kenya and University of Nairobi Immunohistochemistry Laboratory.

\section{Study population}

All patients with confirmed histological diagnosis from endoscopic/ resection specimens of gastric or gastro-oesophageal junction carcinoma, admitted in surgical/radioncology wards, attending surgical/radioncology clinics, endoscopy unit, accident and emergency at Kenyatta

\section{Sampling procedure}

Non-random progressive sampling of patients who meet inclusion criteria until sample size was obtained.

\section{Inclusion criteria}

Patients with confirmed histological diagnosis of gastric or gastrooesophageal junction carcinoma, with viable histologic tissue blocks at $\mathrm{KNH} / \mathrm{UON}$ laboratory and consent to participate in the study.

Patients with radiological diagnosis of gastric or gastro-oesophageal junction tumours awaiting Oesophagoduodenoscopy (OGD) or surgery and consent to participate in the study at $\mathrm{KNH}$, subject to the histopathological examination confirming the diagnosis of carcinoma and a viable tissue block being retrieved from the $\mathrm{KNH} / \mathrm{UON}$ laboratory.

\section{Exclusion criteria}

- Patient who declined consent to participate in the study.

- Patients whose histological diagnosis ruled out carcinoma from OGD specimen.

- $\quad$ Patients with non-viable tissue blocks at KNH/UON pathology laboratory (inadequately fixed/processed or showing crush/ mechanical distortion rendering HER-2 immunostaining difficult or impossible to evaluate).

- Patients whose histology was done in other laboratories other than $\mathrm{KNH} / \mathrm{UON}$.

- Patients whose histological diagnosis indicated secondary tumour or distal squamous cell carcinoma of the oesophagus.

\section{Study setting and sampling}

The study setting was at the Kenyatta National Hospital surgical/ radioncology wards, clinics and endoscopy unit, KNH/UON pathology laboratory.

The study commenced upon approval by the Ethical Committee of the Kenyatta National Hospital/University of Nairobi.

Following patients recruitment, informed consent was obtained and their formalin fixed paraffin embedded (FFPE) tissue blocks were retrieved. Sections were made and staining done using routine Haematoxylin and Eosin stain. The slides were reviewed for quality and quantity of material by a pathologist in KHN/UON laboratories. 
Citation: Hussein AA, Emily R, Omulo TM, Ndaguatha PLW (2014) HER2/Neu Protein Over-Expression in Patients with Gastric and GastroEsophageal Junction Carcinoma Seen at Kenyatta National Hospital, Kenya. J Carcinog Mutagen 5: 186. doi: $10.4172 / 2157-2518.1000186$

Page 4 of 10

Suitable cases were selected and presented for IHC for HER-2 receptors using anti HER-2antibodies.

\section{Immunohistochemistry}

Immunohistochemistry was done using manual method of immunostaining at the University of Nairobi immunohistochemistry laboratory. The IHC method used was Leica Microsystems Novocastra Ready-to-Use Mouse Mouse Monoclonal Antibody HER2 Immunostain (Product code: RTU-CB11). HER-2 protein expression was assessed in carcinoma cells by immunohistochemistry (IHC) in paraffin-embedded $3 \mu \mathrm{m}-5 \mu \mathrm{m}$ tissue sections.

The sectioning and staining was carried out by histotechnologist with a higher National diploma in histology and a wide experience in immunohistochemistry procedure.

Each stained slide was analyzed and interpreted by a pathologist using a validated scoring system for HER-2 assessment criteria specific for gastric and GEJ carcinoma. The slides were read by one primary pathologist and reviewed by a second pathologist as part of further quality assurance.

The Principal investigator was actively involved in the logistics of the study including data capture.

\section{Quality assurance}

Measures for quality assurance were put in place to minimize pre analytical, analytical and post analytical variables. This included:

- Pre-Analytical variables of IHC tests; measures were put in place to avoid effects of over or under fixation and over processing of the FFPE blocks.

-Sectioning and staining- the techniques and procedures for reagent preparation, staining and quality control followed the UON standard operating procedures for routine staining and the standard manufacturers guide for HER-2.

- Interpretation and reporting of the results was done by a pathologist using a validated scoring system.

- $\quad$ Following review by a second pathologist all inconsistent cases were reviewed and reported by a third pathologist (tie breaker).

Data was collected using questionnaires as a tool of data collection. Detailed data was documented on the ratio of male to female's HER-2 over expression, percentage of HER-2 over expression in gastric and gastro oesophageal junction carcinoma, histological type and anatomical site of cancer at which HER-2 over expresses.

\section{Data management and analysis}

A pretested questionnaire was administered for data collection. Consecutive sampling was used to collect data on patients and tissue blocks in the laboratories.

Data was cleaned and entered in SPSS version 21.0 which was used for statistical analysis at the end of data collection. Further data cleaning was done before analysis where errors and inconsistent (conflicting) answers, missing entries and duplicate entries were checked to ensure high quality data. The study population was described using demographic information which was summarized into mean and standard deviations (SD) for age and relative frequencies for sex and residence. Anatomical site and histological type of the tumours was analyzed and presented as percentages.

Prevalence of HER-2 over-expression was analyzed and presented as a percentage of patients with HER-2 positive results; 95\% confidence interval of the prevalence was also presented. Prevalence of HER-2 over-expression was further stratified by the anatomical site and histological type of the tumour. Associations between HER-2 over-expression was done by comparing mean ages across HER-2 status (Positive, Negative or Equivocal) using ANOVA test. Chi square test was used to analyse HER-2 status with categorical variables such as sex, anatomical site and histological type of the tumours. All the tests of associations or comparisons were significant at $5 \%$ ( $p$ value $\leq 0.05$ ) level of significance. The findings were presented using tables and graphs.

\section{Ethical consideration}

The study commenced upon approval by the Department of Surgery (UON) and KNH ethics and research committee. Informed consent was obtained from each participant prior to enrolment in the study. A pre-consent counseling of the participants was carried out. The guardian or next of kin was required to sign consent on behalf of participants who were unable to do so due to unconsciousness, confusion or too sick. Confidentiality; access to detailed information was restricted to the researcher and individuals involved in the study. Feedback of information; all participants were informed of their individual results for immunohistochemistry.

\section{Results}

The study examined 66 cases with gastric or gastro-oesophageal junction carcinoma for HER-2 status. Of the 66 cases studied, 42 cases were from biopsied OGD specimens while 24 cases were from surgically resected specimens.

\begin{tabular}{|l|l|}
\hline Variable & Frequency (\%) \\
\hline Mean age in years (SD) & $60.7(15.0)$ \\
\hline Min-Max & $26-89$ \\
\hline Age category, $\mathbf{n}(\%)$ & $6(9.1)$ \\
\hline Below 40 years & $9(13.6)$ \\
\hline $40-49$ years & $13(19.7)$ \\
\hline $50-59$ years & $16(24.2)$ \\
\hline $60-69$ years & $13(19.7)$ \\
\hline $70-79$ years & $9(13.6)$ \\
\hline $80-89$ years & \multicolumn{2}{|l|}{} \\
\hline Sex & $22(66.7)$ \\
\hline Male & $233.3)$ \\
\hline Female & \\
\hline
\end{tabular}

Table 3: Socio Demographic Characteristics.

The mean age of patients with carcinoma was 60.7 years ( 15.0 years SD) with the youngest being 26 years and the eldest was 89 years. More than $60 \%$ of patients were between the ages of 50 to 79 years. 
Citation: Hussein AA, Emily R, Omulo TM, Ndaguatha PLW (2014) HER2/Neu Protein Over-Expression in Patients with Gastric and GastroEsophageal Junction Carcinoma Seen at Kenyatta National Hospital, Kenya. J Carcinog Mutagen 5: 186. doi: $10.4172 / 2157-2518.1000186$

Page 5 of 10

Majority (66.7\%) were males and more than three-quarters $(77.3 \%)$ resided outside Nairobi. (Table 3, Figures 1 and 2).

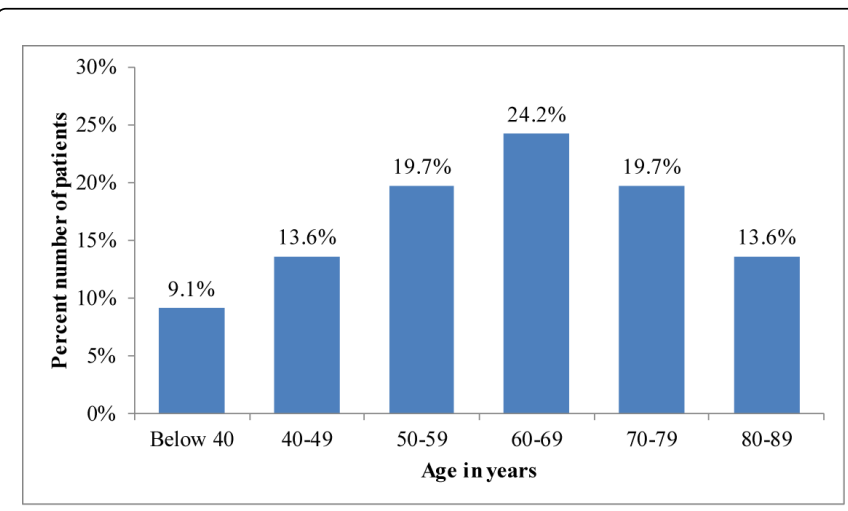

Figure 1: Age distribution.

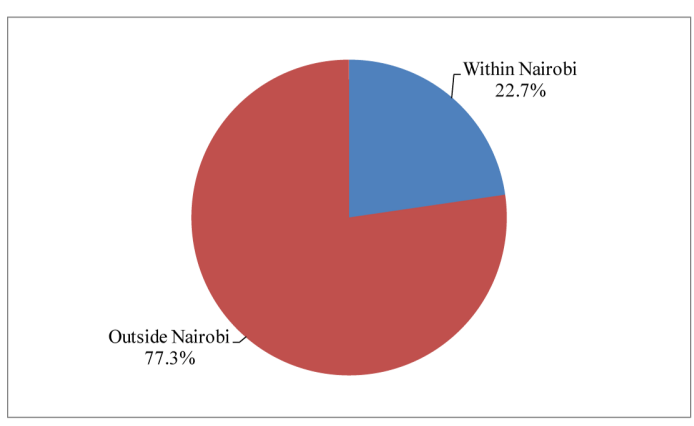

Figure 2: Residence.

All the specimens were interpreted by a primary pathologist for HER-2 status, while the second pathologist was presented with every $5^{\text {th }}$ case $(\mathrm{N}=13)$ for confirmation and quality assurance. Discrepancy cases $(\mathrm{N}=5)$ were confirmed by a third pathologist (tie breaker) as shown in table 4 below.

\begin{tabular}{|l|l|l|l|l|}
\hline Case & $\begin{array}{l}\text { Primary } \\
\text { pathologist }\end{array}$ & $\begin{array}{l}\text { Secondary } \\
\text { pathologist }\end{array}$ & $\begin{array}{l}\text { Third pathologist } \\
\text { (tie breaker) }\end{array}$ & Conclusion \\
\hline Case 1 & +3 & +1 & +1 & +1 \\
\hline Case 2 & +3 & +2 & +3 & +3 \\
\hline Case 3 & +2 & +1 & +2 & +2 \\
\hline Case 4 & +1 & 0 & +1 & +1 \\
\hline Case 5 & +3 & +1 & +1 & +1 \\
\hline
\end{tabular}

Table 4: shows evaluation for 5 discrepancy cases in HER-2 assessment

The above results was based on the consensus panel recommendation for HER-2 scoring system

\section{Anatomical site and histological type of the tumour}

Most tumours were located in the gastric region $(90.9 \%, \mathrm{~N}=60)$. Majority of the histological types were adenocarcinoma $(89.4 \%, \mathrm{~N}=59)$ mainly intestinal $(78.8 \%, \mathrm{~N}=52)$ and diffuse $(9.1 \%, \mathrm{~N}=6)$ while $1.5 \%$ $(\mathrm{N}=1)$ was adenosquamous.

Carcinoma of the gastroesophageal junction accounted for $9.1 \%$ and all were intestinal adenocarcinomas $(\mathrm{N}=6)$ (Table 5 and Figure 3 ).

\begin{tabular}{|l|l|l|}
\hline \multirow{2}{*}{ Variable } & \multicolumn{2}{l|}{ Anatomical site } \\
\cline { 2 - 3 } & $\begin{array}{l}\text { Gastroesophageal } \\
\text { N (\%) }\end{array}$ & $\begin{array}{l}\text { Gastric } \\
\text { N (\%) }\end{array}$ \\
\hline $\begin{array}{l}\text { Number per anatomical site } \\
(\mathrm{n}=66)\end{array}$ & $6(9.1)$ & $60(90.9)$ \\
\hline Histological type & $6(9.1)$ & $59(89.4)$ \\
\hline Adenocarcinoma & $6(9.1)$ & $52(78.8)$ \\
\hline Intestinal & 0 & $6(9.1)$ \\
\hline Diffuse & 0 & $1(1.5)$ \\
\hline Mixed/Unknown & 0 & $1(1.5)$ \\
\hline Adenosquamous & & \\
\hline
\end{tabular}

Table 5: Anatomical site and histological type of tumors.

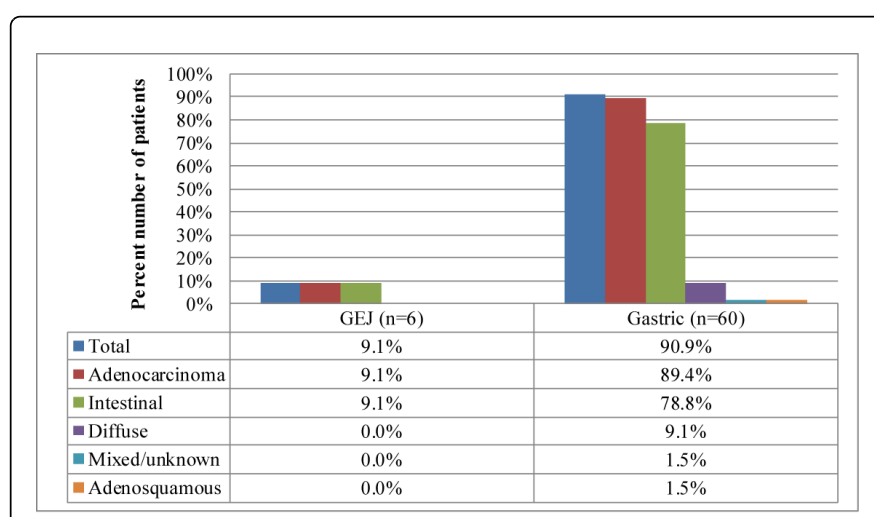

Figure 3: Anatomical site and histological type of tumors

\begin{tabular}{|l|l|}
\hline Variable & Frequency $(\%)$ \\
\hline HER-2 status & $28(42.4)$ \\
\hline Positive $(+3)$ & $6(9.1)$ \\
\hline Equivocal $(+2)$ & $32(48.5)$ \\
\hline Negative $(0,+1)$ & $\mathrm{N}=66$ \\
\hline Total & \\
\hline
\end{tabular}

Table 6: Prevalence of HER-2 over-expression. 
Citation: Hussein AA, Emily R, Omulo TM, Ndaguatha PLW (2014) HER2/Neu Protein Over-Expression in Patients with Gastric and GastroEsophageal Junction Carcinoma Seen at Kenyatta National Hospital, Kenya. J Carcinog Mutagen 5: 186. doi: $10.4172 / 2157-2518.1000186$

Page 6 of 10

\section{HER-2 over-expression}

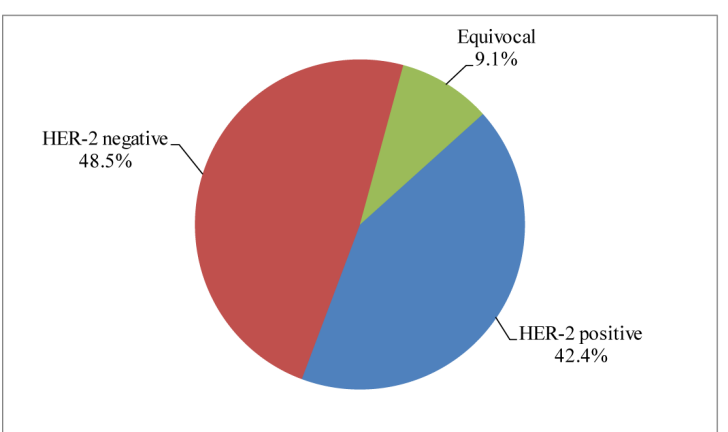

Figure 4: Prevalence.

\section{Demographic Characteristics and HER-2 Over-expression}

Patients with HER-2 over-expression had a mean age of 62.3 years. HER-2 over-expression was $43.2 \%(\mathrm{~N}=19)$ in males and $40.9 \%(9)$ in females. In overall, HER-2 over-expression was not significantly associated with age and gender $(\mathrm{P}>0.05)$. See table 7 and figure 5 .

\begin{tabular}{|l|l|l|l|l|}
\hline Variable & Positive & Negative & Equivocal & P value \\
\hline Mean age (SD) & $62.3(11.9)$ & $60.0(16.0)$ & $60.5(22.1)$ & 0.844 \\
\hline Sex & $19(43.2 \%)$ & $22(50.0 \%)$ & $3(6.8 \%)$ & 0.682 \\
\hline Male & $9(40.9 \%)$ & $10(45.5 \%)$ & $3(13.6 \%)$ & \\
\hline Female &
\end{tabular}

Table 7: Associations between demographic factors and HER-2 overexpression.

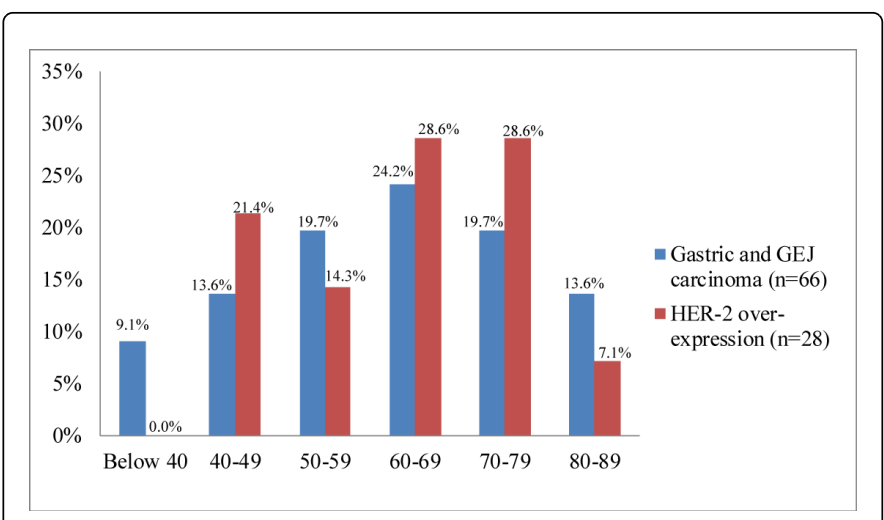

Figure 5: Age distribution and HER-2 over-expression.

\section{HER-2 over-expression and anatomical site}

As illustrated in figure 6 and table 8 below, 3 (50\%) out of the 6 cases of GEJ junction carcinoma had HER-2 over-expression and the other half did not over-express. Gastric carcinoma showed HER-2 over-expression in $41.7 \%$ ( 25 out of the 60 cases), while $48.3 \%$ were negative and $10.0 \%$ were equivocal. The anatomical site was not significantly associated with HER-2 over-expression $(\mathrm{P}>0.05)$.

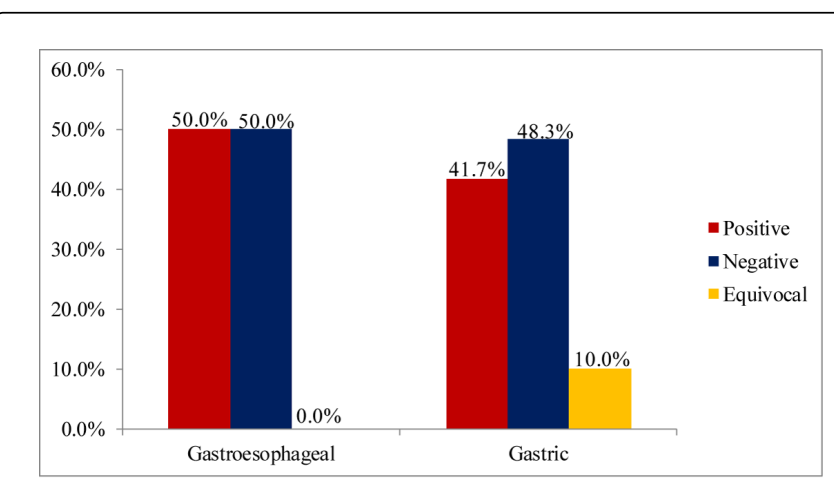

Figure 6: HER-2 over-expression and anatomical sites

\begin{tabular}{|l|l|l|}
\hline \multirow{2}{*}{ Variable } & \multicolumn{2}{|l|}{ Anatomical site } \\
\cline { 2 - 3 } & GEJ & Gastric \\
\hline Positive & $3(50.0 \%)$ & $25(41.7 \%)$ \\
\hline Negative & $3(50.0 \%)$ & $29(48.3 \%)$ \\
\hline Equivocal & $0(0.0 \%)$ & $6(10.0 \%)$ \\
\hline Total & $6(100 \%)$ & $60(100 \%)$ \\
\hline P-value & 1.000 & \\
\hline
\end{tabular}

Table 8: correlation between anatomical site and HER-2 overexpression.

\section{Comparison in HER-2 Over-expression between Gastric and GEJ carcinoma}

In general, out of the 28 cases that showed HER-2 over-expression, 25 cases were found in gastric cancer $(89.3 \%)$ while the remaining 3 cases $(10.7 \%)$ were in the GEJ carcinoma. Table 9.

\begin{tabular}{|l|l|l|l|l|}
\hline Variable & Positive & Negative & Equivocal & P value \\
\hline Anatomical site \\
\hline Gastroesophageal & $3(10.7 \%)$ & $3(9.4 \%)$ & $0(0 \%)$ & 1.000 \\
\hline Gastric & $25(89.3 \%)$ & $29(90.6 \%)$ & $6(100 \%)$ & \\
\hline Total & $28(100 \%)$ & $32(100 \%)$ & $6(100 \%)$ & \\
\hline
\end{tabular}

Table 9: HER-2 over-expression between gastric and GEJ tumours

\section{HER-2 Over-expression and Histological Type}

HER-2 over-expression was found mostly in adenocarcinoma (96.4\%) as compared to $3.6 \%$ in adenosquamous. Intestinal type of gastric adenocarcinoma showed highest rate of HER-2 over-expression (87.5\%) while $12.5 \%$ was of diffuse histological type. In GEJ tumours, all were intestinal type of which half of the cases over-expressed HER-2. See Table 10. 
Citation: Hussein AA, Emily R, Omulo TM, Ndaguatha PLW (2014) HER2/Neu Protein Over-Expression in Patients with Gastric and GastroEsophageal Junction Carcinoma Seen at Kenyatta National Hospital, Kenya. J Carcinog Mutagen 5: 186. doi: $10.4172 / 2157-2518.1000186$

Page 7 of 10

\section{Discussion}

The main study objective was to assess HER 2 over expression in patients with gastric or GEJ carcinoma seen at $\mathrm{KNH}$. The prevalence of HER-2 over-expression was found to be $42.4 \%(\mathrm{~N}=28)$. Despite being on the higher side of the wide range for HER-2 over-expression (6-45\%) 7, most studies have shown a lower rate of HER-2 overexpression (15\%-38\%) [17-19]. However, over-expression rates of up to $53 \%$ and $91 \%$ have been observed $[20,21]$.

The mean age of patients with carcinoma in our study was 60.7 years ( 15.0 years SD). More than $60 \%$ of patients were in the range of 50-79 years. HER-2 over-expression was fairly distributed throughout the age group, with a slight peak at age 60-79 years (28.6\%). This is not statistically significant with no association between HER-2 overexpression and age which is also seen in other studies [46].

\begin{tabular}{|l|l|l|l|l|}
\hline Variable & Positive & Negative & Equivocal & P value \\
\hline Histologic type & \multicolumn{5}{|l|}{} \\
\hline GEJ Site & $3 / 28(10.7 \%)$ & $3 / 32(9.4 \%)$ & $0 / 6(0 \%)$ & 1.000 \\
\hline Adenocarcinoma & \multicolumn{5}{|l|}{} \\
\hline Intestinal & $1 / 28(3.6 \%)$ & $0 / 32(0 \%)$ & $0 / 6(0 \%)$ & 0.517 \\
\hline Gastric Site & $24 / 28(85.7 \%)$ & $29 / 32(90.6 \%)$ & $6 / 6(100 \%)$ & 0.123 \\
\hline Adenosquamous & $21 / 24(87.5 \%)$ & $27 / 29(93.1 \%)$ & $4 / 6(66.7 \%)$ & \\
\hline Intestinal & $3 / 24(12.5 \%)$ & $2 / 29(6.9 \%)$ & $1 / 6(16.7 \%)$ & \\
\hline Adenocarcinoma & $0 / 24(0 \%)$ & $0 / 29(0 \%)$ & $1 / 6(16.7 \%)$ & \\
\hline Intestinal & &
\end{tabular}

Table 10: Associations between histological type of gastric/GEJ carcinoma and HER-2 over-expression.

Amongst our study subjects, gastric cancer was more common in males $(66.7 \%, \mathrm{~N}=44)$ than in females $(33.3 \%, \mathrm{~N}=22)$. This correlates with a distribution ratio of $2: 1$ as seen in the literature. However HER-2 over-expression was $43.2 \%(\mathrm{~N}=19)$ in males and $40.9 \%(\mathrm{~N}=9)$ in females, showing no significant association of HER-2 overexpression and gender. Similar trend is observed in some studies [46].

In view of the above prevalence (42.4\%) in our study as compared to other studies (up to $38 \%$ ), the following explanation is worth mentioning;

Although we cannot entirely exclude the possibility of false positive results given that our specimens were mostly from biopsied OGD specimens $(\mathrm{N}=42)$ which have been shown to have higher false positivity 48 as compared to surgically resected specimens $(\mathrm{N}=24)$.

Geographic and ethnic heterogeneity of tumour associated aberration which exist in solid tumours, may help to explain the differences for HER-2 over-expression in various studies [48-51]. In addition there is paucity of data in our African population for HER-2 over-expression with no specific documented prevalence in African population leaving outside the African continent.
Most studies restricted their evaluation to membrane staining only, excluding staining that appeared cytoplasmic [52-54]. However, because membrane staining can project to the cytoplasm in the twodimensional limitation of the microscopic picture, in our opinion, a definite distinction between an exclusively cytoplasmic and a mainly membranous staining could not be made in some cases. Furthermore, there have been reports of truncated or secreted forms of the HER-2 receptor that are not anchored in the cell membrane $[55,56]$ and that could have been detected immunohistochemically as a nonmembranous staining pattern [57]. In view of these facts, we decided not to restrict our scoring system to membrane staining and, therefore, also considered any case with both membranous and cytoplasmic staining patterns as positive.

In addition, studies with lower rate of HER-2 over-expression were conducted as large cohorts with a larger sample size compared to ours $(\mathrm{N}=66)$ hence this might explain the higher rate in our study.

Specimens which demonstrated weak to moderate complete or basolateral membranous reactivity in more than $10 \%$ of cells $(9.1 \%$, $\mathrm{N}=6$ ) were classified as equivocal $(+2)$. These cases require to undergo FISH test evaluation to classify them as positive or negative for HER-2 over-expression. FISH was not available in our study as alluded earlier in the study limitation. However in the ToGA trial $26 \%$ of the equivocal were FISH positive for HER-2 over-expression, while in a Chinese cohort study, 28.8\% of equivocal turned positive upon FISH evaluation 16, 58. On extrapolation using the above studies, our HER-2 positivity will be expected to rise to $43.9 \%$.

On assessment of HER-2 over-expression in specific anatomical sites, it was observed that $50 \%(\mathrm{~N}=3 / 6)$ of GEJ tumours and $41.7 \%$ $(\mathrm{N}=25 / 60)$ of gastric cancer, over-expressed HER-2. Though the difference is not statistically significant, this trend is similar to other studies which exhibits high HER-2 over-expression in GEJ compared to gastric cancer $[17,23,46]$. HER-2 over-expression may even be higher in oesophageal cancers [17].

In general out of all the 28 cases which revealed HER-2 overexpression, 25 cases were from gastric region $(89.3 \%)$ and the remaining 3 cases $(10.7 \%)$ were from the GEJ. This was attributed to fewer cases of GEJ cancer in our study $(\mathrm{N}=6)$.

On evaluation of histological pattern for HER-2 over-expression, this study shows higher HER-2 over-expression in intestinal type $(87.5 \%, \mathrm{~N}=21)$ compared to diffuse $(12.5 \%, \mathrm{~N}=3)$ and mixed $(0 \%$, $\mathrm{N}=0$ ) for gastric adenocarcinoma. This concurs with other studies comparing HER-2 over-expression and histological types of gastric and GEJ carcinomas $[23,25,26]$. Countries with higher rate of intestinal than diffuse histological type of cancer, had a higher prevalence of HER-2 over-expression [57]. Since the latter is similar to our set up, it may pose a challenge in surgical management outcome and prognosis of our patients.

\section{Conclusion}

HER-2 over-expression is higher in our study (42.4\%) compared to most of the studies, with no correlation to age and gender. Overexpression is predominant in intestinal type of gastric and GEJ adenocarcinomas. 
Citation: Hussein AA, Emily R, Omulo TM, Ndaguatha PLW (2014) HER2/Neu Protein Over-Expression in Patients with Gastric and GastroEsophageal Junction Carcinoma Seen at Kenyatta National Hospital, Kenya. J Carcinog Mutagen 5: 186. doi: $10.4172 / 2157-2518.1000186$
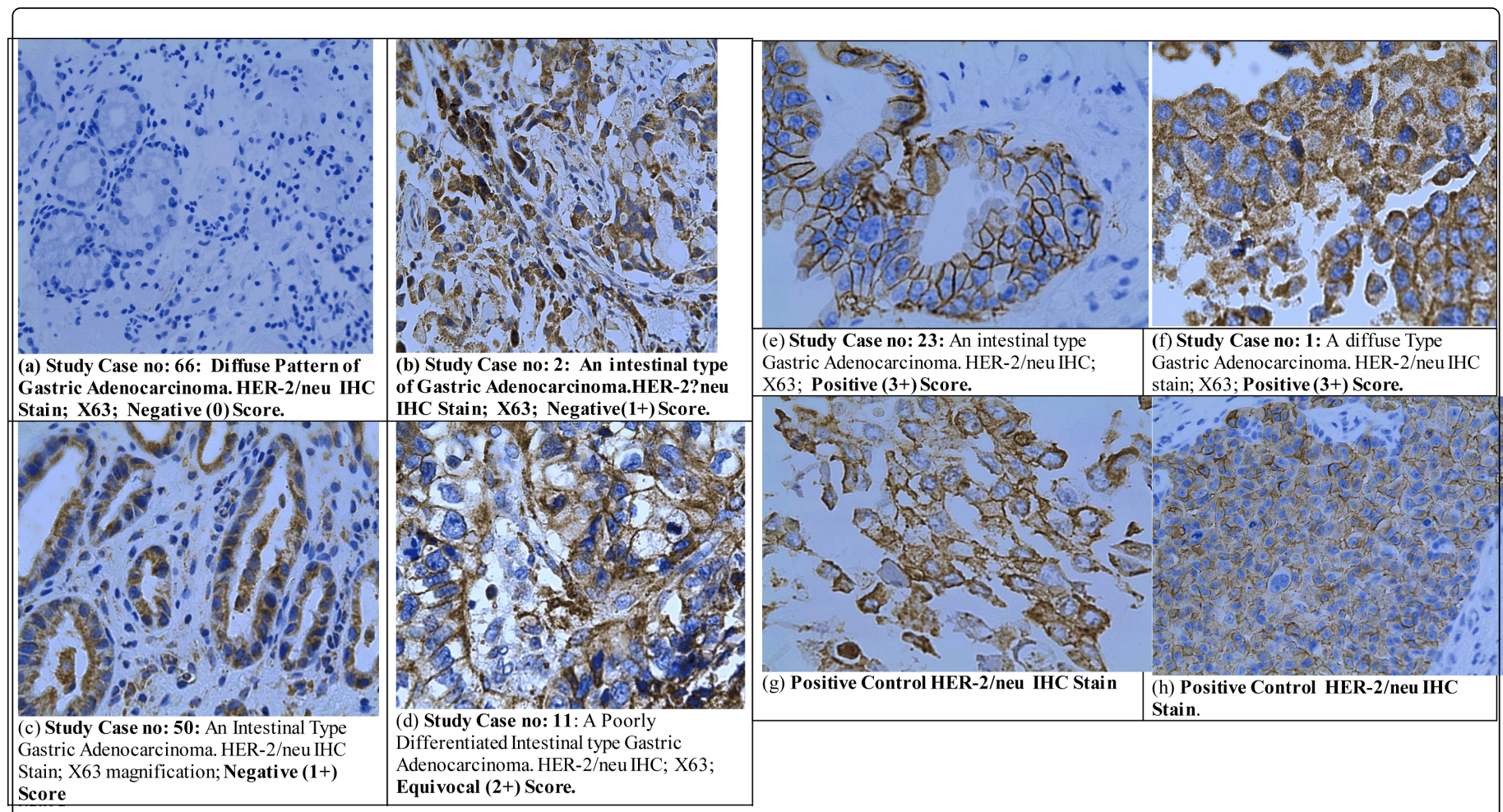
Score

Equivocal (2+) Score.

Photomicrographs: Representative Photomicrographs of Sections Stained for HER-2/neu Protein. (a) Study Case no: 66: Diffuse Pattern of Gastric Adenocarcinoma. HER-2/neu IHC Stain; X63; Negative (0) Score. (b) Study Case no: 2: An intestinal type of Gastric Adenocarcinoma.HER-2?neu IHC Stain; X63; Negative(1+) Score. (c) Study Case no: 50: An Intestinal Type Gastric Adenocarcinoma. HER-2/neu IHC Stain; X63 magnification; Negative (1+) Score . (d) Study Case no: 11: A Poorly Differentiated Intestinal type Gastric Adenocarcinoma. HER-2/neu IHC; X63; Equivocal (2+) Score. (e) Study Case no: 23: An intestinal type Gastric Adenocarcinoma. HER-2/neu IHC; X63; Positive (3+) Score.(f) Study Case no: 1: A diffuse Type Gastric Adenocarcinoma. HER-2/neu IHC stain; X63; Positive (3+) Score. (g) Positive Control HER-2/neu IHC Stain. (h) Positive Control HER-2/neu IHC Stain.

\section{Recommendations}

All advanced gastric and GEJ carcinomas should undergo HER-2 status evaluation due to high prevalence of over-expression in our study.

Cases with HER-2 equivocal results in IHC should undergo FISH analysis to confirm HER-2 status, hence the need to build our local capacity for FISH test.

Further studies with larger cohorts need to be conducted to provide more clarity on prevalence of HER-2 over-expression in our set up.

Use of automated machines for assessing HER-2 status to eliminate possible human errors.

Trastuzumab to be administered as part of combination chemotherapy in patients with advanced gastric and GEJ carcinoma who over-expresses HER-2.

Active advocacy and involvement of the Ministry of Health to minimize cost of HER-2 status evaluation and availability of Trastuzumab as part of combination chemotherapy.

\section{References}

1. Kelley JR, Duggan JM (2003) Gastric cancer epidemiology and risk factors. J Clin Epidemiol 56: 1-9.
2. Jemal A, Bray F, Center MM, Ferlay J, Ward E, et al. (2011) Global cancer statistics. CA Cancer J Clin 61: 69-90.

3. Kubo A, Corley DA (2006) Body mass index and adenocarcinomas of the esophagus or gastric cardia: a systematic review and meta-analysis. Cancer Epidemiol Biomarkers Prev 15: 872-878.

4. Ferlay J, Bray F, Pisani P, et al. Cancer Incidence, Mortality, and Prevalence Worldwide. Globocan 2002. Lyon: IARC, 2004.

5. Nairobi Cancer Registry.

6. Power DG, Kelsen DP, Shah MA (2010) Advanced gastric cancer- slow but steady progress. Cancer Treat Rev: 384-392.

7. Judith M, Heather Jane, Michael B (2010) Transtuzumab utility for Gastric cancer. Connection: 30-32.

8. McFarlane G, Forman D, Sitas F, Lachlan G (2001) A minimum estimate for the incidence of gastric cancer in Eastern Kenya. Br J Cancer 85: 1322-1325.

9. Parkin DM, Whelan SL, Farley J, Raymond L, Young J (2000) Cancer Incidence in five continents VOL V11 ARC scientific publication 143, Lyon.

10. Chokunonga E, Levy LM, Bassett MT, Mauchaza BG, Thomas DB, et al. (2000) Cancer incidence in the African population of Harare, Zimbabwe: second results from the cancer registry 1993-1995. Int J Cancer 85: 54-59.

11. Wabinga HR, Parkin DM, Wabwire-Mangen F, Nambooze S (2000) Trends in cancer incidence in Kyadondo County, Uganda, 1960-1997. Br J Cancer 82: 1585-1592.

12. Ross JS (2009) Breast cancer biomarkers and HER2 testing after 10 years of anti-HER2 therapy. Drug News Perspect 22: 93-106. 
Citation: Hussein AA, Emily R, Omulo TM, Ndaguatha PLW (2014) HER2/Neu Protein Over-Expression in Patients with Gastric and GastroEsophageal Junction Carcinoma Seen at Kenyatta National Hospital, Kenya. J Carcinog Mutagen 5: 186. doi: $10.4172 / 2157-2518.1000186$

Page 9 of 10

13. Jones KL, Buzdar AU (2009) Evolving novel anti-HER2 strategies. Lancet Oncol 10: 1179-1187.

14. Sakai K, Mori S, Kawamoto T, Taniguchi S, Kobori O, et al. (1986) Expression of epidermal growth factor receptors on normal human gastric epithelia and gastric carcinomas. J Natl Cancer Inst 77: 1047-1052.

15. Ross JS, McKenna BJ (2001) The HER-2/neu oncogene in tumors of the gastrointestinal tract. Cancer Invest 19: 554-568.

16. Christa L. Whitney-Miller, David G (2010) HER2 Testing in Gastric and Oesophageal Adenocarcinoma: Emerging Therapeutic Options and Diagnostic Challenges: 49-50.

17. Bang YJ, Van Cutsem E, Feyereislova A, Chung HC, Shen L, et al. (2010) Trastuzumab in combination with chemotherapy versus chemotherapy alone for treatment of HER2-positive advanced gastric or gastrooesophageal junction cancer (ToGA): a phase 3, open-label, randomised controlled trial. Lancet 376: 687-697.

18. Hofmann M, Stoss O, Shi D, Büttner R, van de Vijver M, et al. (2008) Assessment of a HER2 scoring system for gastric cancer: results from a validation study. Histopathology 52: 797-805.

19. Y. Bang, H. Chung, A. Sawaki, J. Xu, L. Shen et al. (2008) HER2positivity rates in advanced gastric cancer (GC): Results from a large international phase III trial. J Clin Oncol (Meeting Abstracts) : 4526-4528

20. Jørgensen JT (2010) Targeted HER2 treatment in advanced gastric cancer. Oncology 78: 26-33.

21. Allgayer H, Babic R, Gruetzner KU, Tarabichi A, Schildberg FW, et al (2000) c-erbB-2 is of independent prognostic relevance in gastric cancer and is associated with the expression of tumor-associated protease systems. J Clin Oncol 18: 2201-2209.

22. Kunz PL, Mojtahed A, Fisher GA, Ford JM, Chang DT, et al. (2012) HER2 expression in gastric and gastroesophageal junction adenocarcinoma in a US population: clinicopathologic analysis with proposed approach to HER2 assessment. Appl Immunohistochem Mol Morphol 20: 13-24.

23. Tanner M1, Hollmén M, Junttila TT, Kapanen AI, Tommola S, et al. (2005) Amplification of HER-2 in gastric carcinoma: association with Topoisomerase IIalpha gene amplification, intestinal type, poor prognosis and sensitivity to trastuzumab. Ann Oncol 16: 273-278.

24. Gravalos C, Marquez A, Garcia-Carbonero R (2007) Correlation between HER2/neu over-expression/ amplification and clinicopathological parameters in advanced gastric cancer patients: a prospective study. ASCO 2007 Gastrointestinal Cancers Symposium.

25. Lordick F, Bang YJ, Kang YK, (2007) HER2-positive advanced gastric cancer: similar HER2-positivity levels to breast cancer. Eur J Cancer Suppl: 3541-3545.

26. Matsubara J, Yamada Y, Hirashima Y, Takahari D, Okita NT, et al. (2008) Impact of insulin-like growth factor type 1 receptor, epidermal growth factor receptor, and HER2 expressions on outcomes of patients with gastric cancer. Clin Cancer Res 14: 3022-3029.

27. Park DI, Yun JW, Park JH, Oh SJ, Kim HJ, et al. (2006) HER-2/neu amplification is an independent prognostic factor in gastric cancer. Dig Dis Sci 51: 1371-1379.

28. Koeppen HK, Wright BD, Burt AD, Quirke P, McNicol AM, et al. (2001) Overexpression of HER2/neu in solid tumours: an immunohistochemical survey. Histopathology 38: 96-104.

29. Slamon DJ, Godolphin W, Jones LA, Holt JA, Wong SG, et al. (1989) Studies of the HER-2/neu proto-oncogene in human breast and ovarian cancer. Science 244: 707-712.

30. Oliver s, Martina s, dirk z, Henkel T, et al. (2010) HER2 diagnostic in gastric cancer. Connection: 36-37.

31. Gong SJ, Jin CJ, Rha SY, Chung HC (2004) Growth inhibitory effects of trastuzumab and chemotherapeutic drugs in gastric cancer cell lines. Cancer Lett 214: 215-224.

32. Sastre J, Garcia Saenz GA, Diaz Rublo E (2006) Chemotherapy for gastric cancer. World J Gastroenterol: 2004-2213.

33. Barok M, Isola J, Palyi-Krekk Z,Nagy P, Juhász I, et al.(2007) Trastuzumab causes antibody-dependent cellular cytotoxicity-mediated growth inhibition of sub macroscopic JIMT-1 breast cancer xenografts despite intrinsic drug resistance. Mol Cancer Ther: 2065-2072.

34. Hudis CA (2007) Trastuzumab--mechanism of action and use in clinical practice. N Engl J Med 357: 39-51.

35. Musolino A, Naldi N, Bortesi B, Pezzuolo D, Capelletti M, et al. (2008) Immunoglobulin $\mathrm{G}$ fragment $\mathrm{C}$ receptor polymorphisms and clinical efficacy of trastuzumab-based therapy in patients with HER-2/neupositive metastatic breast cancer. J Clin Oncol 26: 1789-1796.

36. Piccart-Gebhart MJ, Procter M, Leyland-Jones B, Goldhirsch A, Untch $M$, et al. (2005) Trastuzumab after adjuvant chemotherapy in HER2positive breast cancer. N Engl J Med 353: 1659-1672.

37. Romond EH, Perez EA, Bryant J, Suman VJ, Geyer CE Jr, et al. (2005) Trastuzumab plus adjuvant chemotherapy for operable HER2-positive breast cancer. N Engl J Med 353: 1673-1684.

38. Slamon DJ, Leyland-Jones B, Shak S, Fuchs H, Paton V, et al. (2001) Use of chemotherapy plus a monoclonal antibody against HER2 for metastatic breast cancer that overexpresses HER2. N Engl J Med 344: 783-792.

39. Cortas-Funes H, Rivera F, Ales I, et al. Phase II of trastuzumab and cisplatin in patients with advanced gastric cancer (AGC) with HER2/neu over-expression/ amplification. 2007 ASCO Annual Meeting Proceedings, J Clin Oncol 2007; 25:18; 4613-4616.

40. Van Cutsem E, Kang Y, Chung H, Shen L, Sawaki A, et al. (2009). Efficacy results from the ToGA trial: A phase III study of trastuzumab added to standard chemotherapy (CT) in first-line human epidermal growth factor receptor 2 (HER2)-positive advanced gastric cancer (GC). J Clin Oncol: 4509-4513.

41. Nicholas G, Cripps C, Au H-J, et al. Early results of a trial of trastuzumab, cisplatin, and docetaxel (TCD) for the treatment of metastatic gastric cancer overexpressing HER-2. In: ESMO. Ann Oncol, 2006; 1105:

42. Jemal A, Siegel R, Xu J, Ward E (2010) Cancer statistics, 2010. CA Cancer J Clin 60: 277-300.

43. Dikken JL, Jansen EP, Cats A, Bakker B, Hartgrink HH, et al. (2010) Impact of the extent of surgery and postoperative chemoradiotherapy on recurrence patterns in gastric cancer. J Clin Oncol 28: 2430-2436.

44. Van Custom, Shitara K, Ruschoff J (2009). Trastuzumab added to standard chemotherapy (CT) as first-line treatment inhuman epidermal growth factor receptor 2(HER2)-positive advanced gastric cancer (GC): efficacy and safety results from the Phase III ToGA trial . ECCO15-34th ESMO MultidisciplinaryCongress.Berlin, Germany,.

45. Middleton LP, Price KM, Pamela Puig MA, Heydon LJ, Tarco E, et al. (2009) Implementation of American Society of Clinical Oncology/ College of American Pathologists HER2 Guideline Recommendations in a Tertiary Care Facility Increases HER2 Immunohistochemistry and Fluorescence In Situ Hybridization Concordance and Decreases the Number of Inconclusive Cases. Arch Pathol Lab Med: 775-780.

46. Yan SY, Hu Y, Fan JG, Tao GQ, Lu YM, et al. (2011) Clinicopathologic significance of HER-2/neu protein expression and gene amplification in gastric carcinoma. World J Gastroenterol 17: 1501-1506.

47. Yalai Bai, Huan Cheng, Jennifer B, Neumeister V, Kumar S, et al. (2013) Comparison of HER2 and Phospho-HER2 Expression between Biopsy and Resected Breast Cancer Specimens Using a Quantitative Assessment Method.

48. Johansson B, Mertens F, Mitelman F (1991) Geographic heterogeneity of neoplasia-associated chromosome aberrations. Genes Chromosomes Cancer 3: 1-7.

49. Symvoulakis EK, Zaravinos A, Panutsopulos D, Zoras O, Papalambros E, et al. (2007) Highly conserved sequence of exon 15 BRAF gene and KRAS codon 12 mutation among Greek patients with colorectal cancer. Int J Biol Markers 22: 12-18.

50. House MG, Wistuba II, Argani P, Guo M, Schulick RD, et al. (2003) Progression of gene hypermethylation in gallstone disease leading to gallbladder cancer. Ann Surg Oncol 10: 882-889.

51. Nagahashi M, Ajioka Y, Lang I, Szentirmay Z, Kasler M, et al. (2008) Genetic changes of p53, K-ras, and microsatellite instability in 
Citation: Hussein AA, Emily R, Omulo TM, Ndaguatha PLW (2014) HER2/Neu Protein Over-Expression in Patients with Gastric and GastroEsophageal Junction Carcinoma Seen at Kenyatta National Hospital, Kenya. J Carcinog Mutagen 5: 186. doi: 10.4172/2157-2518.1000186

Page 10 of 10

gallbladder carcinoma in high-incidence areas of Japan and Hungary. World J Gastroenterol 14: 70-75.

52. Hynes NE, Stern DF (1994) The biology of erbB-2/neu/HER-2 and its role in cancer. Biochim Biophys Acta 1198: 165-184.

53. Yokota J, Yamamoto T, Toyoshima K, Terada M, Sugimura T, et al. (1986) Amplification of c-erbB-2 oncogene in human adenocarcinomas in vivo. Lancet 1: 765-767.

54. Kameda T, Yasui W, Joshida K, Tsujino T, Nakayama H, et al. (1990) Expression of ERBB2 inhuman gastric carcinomas: Relationship between p185ERBB expression and the gene amplication. Cancer Res 50: 8002-8009
55. Yamamoto T, Ikawa S, Akiyama T, Semba K, Nomura N, et al. (1986) Similarity of protein encoded by the human c-erb-B-2 gene to epidermal growth factor receptor. Nature 319: 230-234.

56. Chariyalertsak S, Sugano K, Ohkura H, Mori Y (1994) Comparison of cerbB-2 oncoprotein expression in tissue and serum of patients with stomach cancer. Tumour Biol 15: 294-303.

57. Ling Shan, Jianming Y, Ning Lu (2013) HER 2 expression and relevant clinico-pathological features in gastric and gastroesophageal adenocarcinoma in Chinese population. Diagnostic Pathology: 76. 